\title{
Research on Credit Risk Agglomeration and Control about P2P Network Lending Platform
}

\author{
Dong Xiaohong ${ }^{1, a, *}$ \\ ${ }^{1}$ Institute of Finance, Harbin University of Commerce, Heilongjiang, Harbin, China \\ ${ }^{1}$ Northeast Asia Service Outsourcing Research Workstation, Heilongjiang, Harbin, China \\ ${ }^{1}$ Harbin University of Commerce of Postdoctoral Research Station of Applied Economics, \\ Heilongjiang, Harbin, China \\ a33587015@qq.com \\ *corresponding author
}

Keywords: P2P network lending; Internet finance; credit risk clustering

\begin{abstract}
P2P network loan industry which are rapid development has solved the problem that our country could not meet the financing needs of small and micro enterprises and personal financial needs. The explosive growth of the network-lending industry faced of significant credit risk of agglomeration and diffusion. In this paper, we analyzed the situation of credit risk accumulation and diffusion of P2P network lending platform under the current conditions, we put forward a clear access threshold of P2P lending platform, and established and improved the industry credit system, and built multi-level P2P credit supervision system Suggestions.
\end{abstract}

\section{Introduction}

P2P network lending platform is one of the Internet financial model from 2007 after the introduction of China, its development is particularly rapid. To a certain extent, which changed the traditional financial lending model. This model is different from the traditional commercial bank loans, private loans and new loans to meet the current economic situation, Individual idle funds deposited into the bank and can not bring value-added assets for their own. P2P network borrowing provides an investment channel for investment fund idle. According to statistics, China's active P2P network lending platform has more than 300, the financing scale from 20 million in 2007 to 3 trillion yuan in2016. As of November 2016, P2P network lending platform for the turnover of 219.734 billion yuan, the monthly growth of 16.53 .2015 November to November 2016, the cumulative 4226.27 million investors, the borrower accumulated 13.6678 million passengers. Along with the rapid development of P2P network lending, which also exposed a series of problems, such as fuzzy positioning, lack of supervision and so on. In the legal risk, credit risk, market risk, operational risk and other risks, credit risk is the P2P network lending platform is the biggest problem facing. How to effectively resolve the credit risk, to promote the orderly development of Internet banking market, an urgent need to solve the problem. Therefore, through the credit risk clustering analysis of the P2P network lending platform, the control method and suggestion of platform credit risk are put forward. 


\section{P2P network credit connotation}

The bank supervision committee and the micro-credit alliance documents pointed out that there are funds and financial investment ideas of individuals, through a third-party network platform matchmaking, the use of credit loans to other borrowing needs. the intermediary is responsible a detailed inspection for the borrower's economic efficiency, management level, development prospects and so on, and they charge management fees and service fees and other income. This mode of operation is based on the "Contract Law", in fact, it is a way of private lending, as long as the loan interest rate does not exceed 4 times the bank loan interest rate over the same period, and it is legal.

On the P2P lending platform, the borrower publishes funding needs and real personal information. At the same time, the lenders have idle funds based on the borrower's qualifications from the capital requirements, past credit records, the size of the company, cash flow capacity and the ability to repay on time and other aspects of careful review, and to review, High-quality borrowers to carry out borrowing activities. The main business of P2P network borrowing is to borrow money to small and medium-sized enterprises with small capital requirement and short borrowing period to solve their borrowing difficulties, which supplement and perfect the existing financial loan system. P2P network lending platform has become the most powerful financial network, Transaction process always show the two sides of the transaction fast, convenient and efficient, but also it can effectively reduce transaction costs. According to statistics, by the end of 2015 , the total number of small and medium-sized enterprise loans accounted for more than $80 \%$ of the total borrowing amount of the P2P network lending platform. The emergence of P2P network credit to solve the problem of small and medium enterprises borrowing, basically to meeting the individual business loans, individual businesses and consumers, the needs of public financial management. Therefore, its emergence is not accidental, but it is the inevitable outcome of the times in the Internet financial continue to impact the traditional financial business .

\section{Analysis of Credit Risk Formation and Agglomeration in P2P Network Ending Platform}

\subsection{Analysis of Credit Risk Aggregation about Credit Subject}

\subsubsection{Borrower's Credit Risk}

Borrower's risk can be divided into pre-lending risk, credit risk and post-lending risk in accordance with operating procedures. In view of P2P network credit platform to collect the credit side of the credit situation is fragmented, which can not fully consider the credit risk, this situation led to pre-loan risk; many P2P network platform will not follow-up funds, which can not control borrowing People's movements, resulting in the risk of credit. In the collection process, there may be borrowers overdue loans, which funds can not be recovered, it caused the risk of post-mortem.

\subsubsection{Lender's Credit Risk}

Between the platform and the lender, Credit risk is outstanding. At present most of the platform is not only as an intermediary, but as a different role, there are auditors, sponsors, money managers, etc., which will lead to some P2P platform to get away,which lenders increase investment risk. First, if the platform itself guarantees, which ignoring the potential threat to the lender, resulting in risks and benefits of reality distortion. Second, the platform which use the lender's capital self-financing will violate the illegal fund-raising bottom line. Finally, the lender's funds through the third-party payment to the P2P platform account, because there is no third-party payment regulatory power, which capital flow is unknown. 


\subsection{Analysis of Credit Risk Agglomeration of Credit Environment on the Formation}

\subsubsection{Entry and Exit Mechanism}

Whether the development of better lending platform, or stand up to the test of time soon collapse of the platform, they all have the same problem that credit evaluation system is imperfect. First of all, the user's personal basic information such as name, ID number, valid bank card number, address, telephone number, etc. included in the scope of credit assessment standards; secondly, the user's personal basic information such as name, , Similar to Lu Jin by such a platform, you need to provide a guarantee fee, and bring the appropriate materials to the store to sign; In addition, many of the platform will be overdue repayment of users in the form of a similar blacklist, which the information released, But these "blacklist" is only short-term or temporary, if the user complete the repayment, the platform will be removed from the blacklist.

\subsubsection{Credit system}

It is lack of a unified and authoritative credit institutions as a guarantee. P2P platform in recent years into the rapid growth stage, and they lack of authoritative credit protection platform,which don't have the user platform to take credit evaluation. Some of the platforms have a certain evaluation system, but the evaluation basis is too weak to play a role and effect,which is an urgent need to establish a unified and authoritative credit institutions To protect the security of P2P platform operations.

\section{Risk Control Measures}

\subsection{Clear Borrowing Threshold for P2P Access Platform}

\subsubsection{Enhance the Registered Capital}

At present, the industry's access threshold is low, which is low cost, and online lending market demand to build a P2P website platform, which will lead to the proliferation of online lending platform, uneven. As the industry is in the early stages of development, many provisions in the network loan, borrowing conditions are not physical financing platform for sound.

\subsubsection{Improve the Qualification Requirements of Managers}

P2P network lending is a technology-intensive and knowledge-intensive sectors, Therefore, professionals is essential. We should strengthen the Internet and financial related personnel training, in particular, we should also be proficient in both computer and financial fields of professional and technical personnel. Large data age requires proficient computer professional and technical personnel to tap the useful information behind the data to prevent the use of customer information by criminals to prevent the platform hackers to protect the security of investor funds, while it will P2P network lending platform for the healthy development of essential that financial innovation talent can develop suitable for the market Need high-quality financial products.

\subsection{Establish and Improve the Industry Credit Information System}

\subsubsection{Open Credit Information}

In the protection of personal privacy information security circumstances, we achieve a nationwide credit file sharing. As mentioned above, China's current credit file is scattered in various organs and departments or enterprises and institutions, and the departments and units are independent of each other therefore it is difficult to achieve file information sharing. In the establishment of a unified national credit institutions, the file information would be integrated that file information sharing is relatively easy. The establishment of credit system sharing mechanism 
needs to provide legal, policy, supervision, technology, personnel and other aspects of protection. To support the whole sharing activities and links, to ensure the sharing of credit information according to law; and to support technology and personnel to protect the privacy of the main credit and information security, the legitimate rights and interests are not violated. Unified credit institutions in the country for the P2P platform to share credit file information, the first clear whether the P2P platform access to credit file information qualification, classification of credit information classification management that clear the various P2P platform query authority to meet the P2P platform specialization Of the service needs. P2P platform should also be allowed to the extent permitted by law disclosure of the borrower's credit status, platform operation, but also to disclose platform operation history of overdue risk situation.

\subsubsection{To Build a New Mode of Credit}

The current P2P platform credit, in terms of information submitted to the main type of business, data sources, information subject and technical level which are different from the central bank's credit system, directly with the central bank credit system docking is not yet mature. In view of this, we should consider the development of an independent network credit credit information system responsible for the collection and storage of relevant data, while access to the central bank credit system reserved interface, when the system data quality is high, the data provider reporting capabilities, technical support And other aspects are the more mature and complete, then we would consider the Internet financial credit data, information into the central bank credit information system, so as to achieve a wider range of information integration and sharing.

\section{Acknowledgements}

This paper is supported by Heilongjiang Province philosophy of social science projects (16JYE01)

\section{References}

[1] Riza Emekter, Yanbin Tu, Benjamas Jirasakuldech, Min Lu,(2015) Evaluating credit risk and loan performance in online Peer-to-Peer (P2P) lending. Applied Economics,1,31-35.

[2] Xinglong W,(2013)Analysis on the Status Quo and Supervision Methods of Online Peer-to peer Lending in China.South China Finance, 3,120-124.

[3] Eunkyoung Lee, Byungtae Lee, Myungsin Chae,(2012)Herding behavior in online P2P lending: An empirical investigation. Journal Electronic Commerce Research and Applications, 5,495- 503.

[4] Xie Chaoyang, Wang Jiao,( 2015)Research on Credit Risk of P2P Network Lending Platform. Finance, 01,1115.

[5] Paul Slattery,(2013)Square Pegs in a Round Hole:SEC Regulation of Online Peer-to-peer Lending and CFPB Alternative. Yale Jour-nal on Regulation . 4,43-46.

[6] Berkovich,E,(2011)Search and herding effects in peer-to-peer lending: evidence from prosper. com. Annals of Finance . 6,29-32. 